\title{
Literatur- und Abkürzungsverzeichnis
}

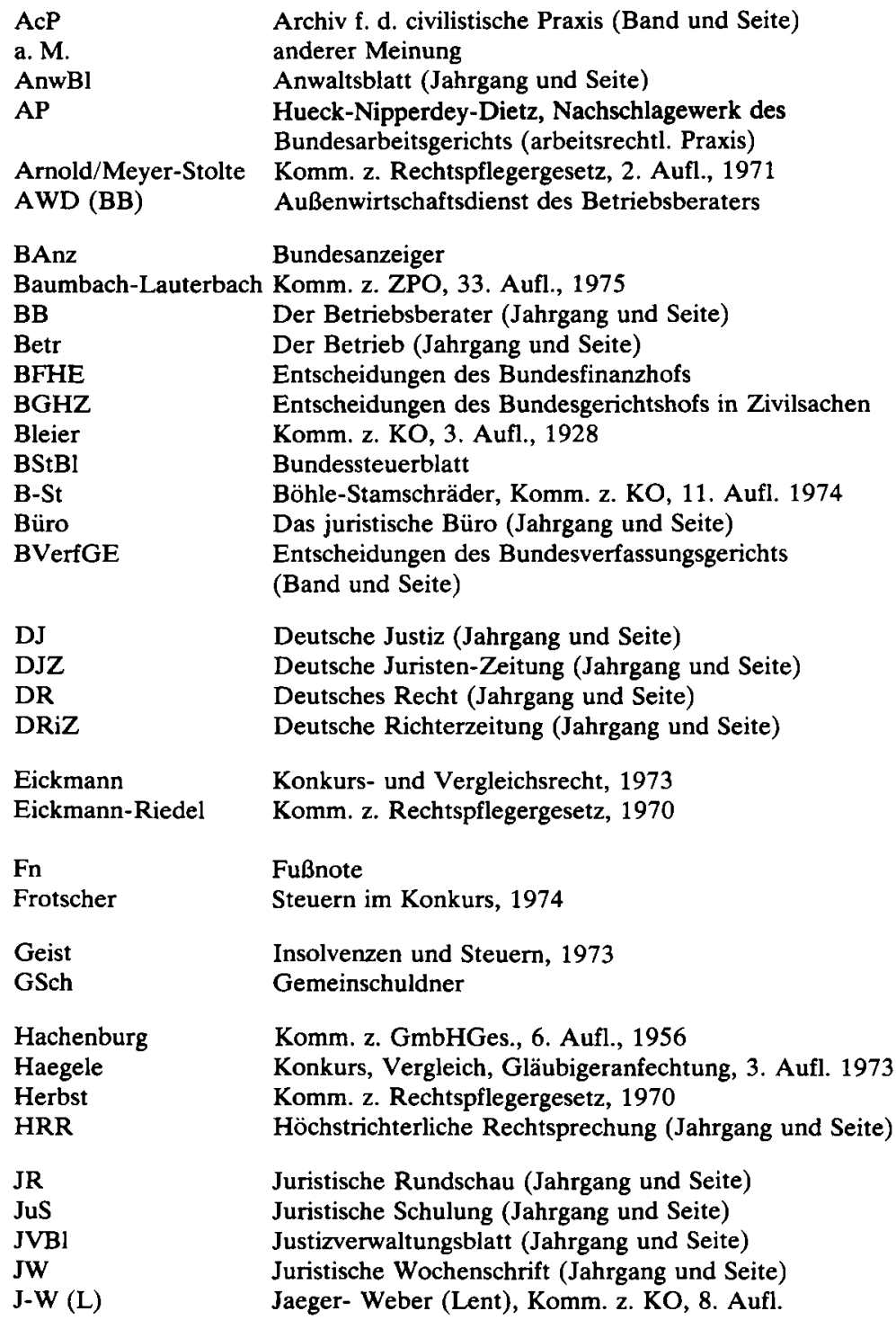


KGJ

KTS

KuT

L

LM

LZ

$\mathrm{Ma}$

MDR

M-K

M-M

Mohrbutter
Jahrbuch f. Entscheidungen des Kammergerichts

Konkurs-, Treuhand- und Schiedsgerichtswesen

(Jahrgang und Seite)

Konkurs und Treuhand (Jahrgang und Seite)

Lauterbach, Kostengesetze, 16. Aufl.

Lindenmaier-Möhring, Nachschlagewerk f. d.

Entscheidungen des Bundesgerichtshofs

Leipziger Zeitschrift für Deutsches Recht

(Jahrgang und Seite)

Markel, Komm. z. GKG, 1967

Monatsschrift f. Deutsches Recht (Jahrgang und Seite)

Mentzel-Kuhn, Komm. z. KO, 7. Aufl. 1962

Meyer-Meulenbergh, Komm. z. GenG, 9. Aufl., 1961

Handbuch des gesamten Vollstreckungs- und Insolvenzrechts,

2. Aufl., 1974

Mohrbutter-Haarmann Leitfaden f. Vergleichs- und Konkursverwalter, 1958

Mot.

Begründung des Entwurfs einer Konkursordnung

NJW

Neue Juristische Wochenschrift (Jahrgang und Seite)

OLGE

Sammlung der Entscheidungen der Oberlandesgerichte

(Band und Seite)

Pagenstecher-Grimm

Palandt (-Bearb.)

Petersen-Kleinfeller

$\mathrm{Rn}$

Rosenberg-Schwab

Rpfleger

Der Konkurs, 1968

Komm. z. BGB u. a., 33. Aufl. 1974

Komm. z. KO, 4. Aufl., 1900

Randnummer

Zivilprozeßrecht, 11. Aufl., 1974

Der Deutsche Rechtspfleger (Jahrgang und Seite)

Schrader-Bauer

Schönke-Baur

Serick

Stein-Jonas-Pohle

Stöber

Thomas-Putzo

WM

Wolff

Zöller (-Bearb.)

ZZP
Konkurs und Vergleich (Handbuch f. d. Rechtspraxis, Bd. 3)

3. Aufl., 1973

Zwangsvollstreckung-, Konkurs- und Vergleichsrecht,

9. Aufl., 1974

Eigentumsvorbehalt und Sicherungsübertragung, 3 Bde., (1963-1970)

Komm. z. ZPO, 18. Aufl., 1975

Forderungspfändung, 4. Aufl., 1975

Komm. z. ZPO, 8. Aufl., 1974

Wertpapier-Mitteilungen (Rechtsprechungsteil)

Komm. z. KO, 1921

Komm. z. ZPO, 11. Aufl., 1973

Zeitschrift für Zivilprozeß (Jahrgang und Seite) 